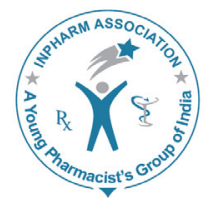

\title{
Adverse Drug Reactions in Patients put on Multi Drug Resistant Tuberculosis (MDR-TB) Treatment in Seven Districts of Central Gujarat
}

\author{
Sangita Vashrambhai Patel ${ }^{1 *}$, Nimavat Kapil Bhikhubhai ${ }^{2}$, Alpesh Bhimabhai \\ patel $^{3}$, Kalpita Samrat Shringarpure ${ }^{4}$, \\ Kedar Gautambhai Mehta ${ }^{5}$ and Lipy Krishnakumar Shukla ${ }^{6}$ \\ 1,2,4,6* Department of Preventive and Social Medicine, Baroda Medical College, Vadodara, Gujarat, India. \\ ${ }^{3}$ Department of Preventive and Social Medicine, Smt. N.H.L. Municipal Medical College, Ahmedabad, India. \\ ${ }^{5}$ Department of Preventive and Social Medicine, GMERS, Gotri, Vadodara, Gujarat, India.
}

\begin{abstract}
Aim: To study the Adverse drug reactions (ADRs) experienced by MDR TB patients put on DOTS plus regimen. Material and Methods: The longitudinal cohort study was conducted by following a cohort of 142 MDR TB patients registered for DOTS plus therapy in 2010 under Revised National Tuberculosis Control Programme (RNTCP). Two follow ups were taken in a cohort of 142 MDR TB patients, first at completion of 6 months of treatment and second after completion of 24 months of treatment. Subjects were interviewed to study side effects of DOTS plus regimen. Results: After 6 months of treatment, 48.59\% (69) patients developed ADRs and between 6 months and 24 months of treatment $54.93 \%$ (78) patients developed ADRs out of total 142 at both the milestones. GI disturbances were $54.9 \%$ at 1 st follow up and $46.54 \%$ at second follow up. Other side effects like headache, arthralgias, decreased hearing and skin reactions were also reported in varying frequencies. Average duration of ADRs was $60-90$ days at both the follow ups. $62.68 \%$ of all ADRs were managed by symptomatic treatment and dose reduction was done in $4.47 \%$ of the patients in $2^{\text {nd }}$ follow up. Conclusion: ADRs were experienced by more than half of the patients in the study and they increased as the duration of treatment increased. GI disturbances, Headache and Arthalgia were most common ADRs among patients. Most of them were managed by symptomatic treatment.
\end{abstract}

Key words: Adverse drug reactions, ADR management, Compliance, DOTS plus, MDR-TB, RNTCP, Treatment adherence.

\begin{tabular}{|l|l|}
\hline \multicolumn{2}{|c|}{ Access this article online } \\
\hline \multirow{3}{*}{ Journal Sponsor } & \\
\hline & $\begin{array}{l}\text { Website: } \\
\text { www.jyoungpharm.org }\end{array}$ \\
\cline { 2 - 2 } & $\begin{array}{l}\text { DOI: } \\
10.5530 / \text { /jyp.2015.4s.3 }\end{array}$ \\
& \\
\hline
\end{tabular}

\section{INTRODUCTION}

*Address for correspondence:

Dr. Sangita Vashrambhai Patel, Associate professor, Department of Preventive and Social medicine, Medical College, Baroda. Address:5, Gokul society, Sindhawai Mata Road, Pratapnagar, Vadodara, Gujarat, India.E-mail: sangita_psm@yahoo.co.in 


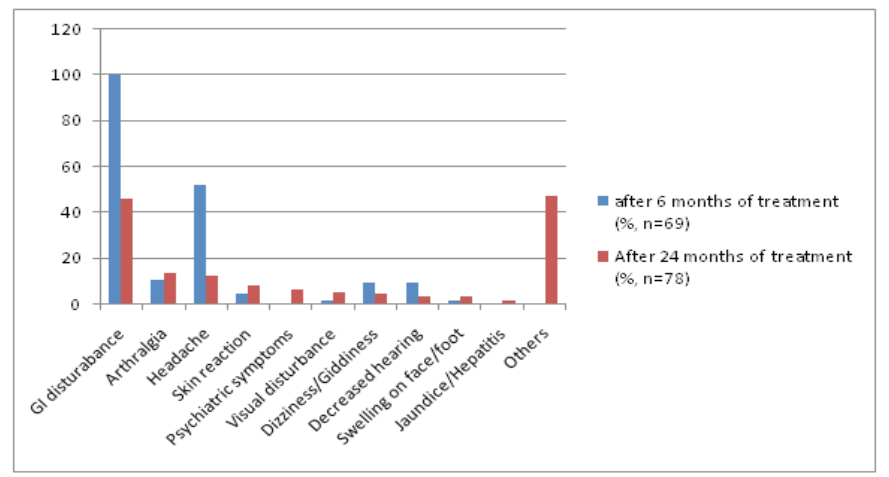

\begin{tabular}{|c|c|c|}
\hline \multicolumn{3}{|c|}{ ADRs after 6 months } \\
\hline Most Common & Common & Least Common \\
\hline $\begin{array}{l}\text { 1.GIDisturbances } \\
\text { 2.Headache }\end{array}$ & 1. Arthralgia & $\begin{array}{l}\text { 1. Skin reactions } \\
\text { 2.Visual disturbance } \\
\text { 3.Dizziness/Giddiness } \\
\text { 4.Decreased hearing } \\
\text { 5.Swelling on face/foot }\end{array}$ \\
\hline \multicolumn{3}{|c|}{ ADRs after 24 months } \\
\hline Most Common & Common & Least Common \\
\hline 1.GIDisturbances & $\begin{array}{l}\text { 1. Arthralgia } \\
\text { 2. Headache }\end{array}$ & $\begin{array}{l}\text { 1.Skin reactions } \\
\text { 2.Psychiatric symptoms } \\
\text { 3.Visual disturbance } \\
\text { 4.Dizziness/Giddiness } \\
\text { 5.Decreased hearing } \\
\text { 6.Swelling on face/foot } \\
\text { 7.Jaundice/Hepatitis }\end{array}$ \\
\hline
\end{tabular}

Graphical Abstract

DOTS-Plus guidelines for treatment of MDR-TB known as Category IV (Cat IV) regimen. Completing MDR TB therapy is more challenging than completing first-line TB therapy. One of the many reasons is the more toxic secondline drugs used to treat MDR TB often cause disruptive adverse reactions, ${ }^{5}$ which are, many a times, mentioned as obstacles in the management of MDR-TB patients. Limited evidence of ADRs in MDR TB patients is available from resource-limited settings like India. This study was taken up to evaluate frequency of occurrence of various ADRs, their duration and management in MDR-TB patients during the course of treatment.

\section{MATERIALS AND METHODS}

This DOTS Plus site is receiving the inflow of MDRTB patients from seven districts. Treatment is provided according to Category 4 regimen under RNTCP.

Category IV regimen ${ }^{6}$ comprises of 6 drugs- kanamycin, ofloxacin (levofloxacin), ethionamide, pyrazinamide, ethambutol and cycloserine during 6-9 months of the Intensive Phase and 4 drugs- ofloxacin (levofloxacin), ethionamide, ethambutol and cycloserine during the 18 months of the Continuation Phase (for weight bands 16-
25, 26-45 and more than $45 \mathrm{Kgs})$. p-aminosalicylic acid (PAS) is included in the regimen as a substitute drug if any bactericidal drug (K, Ofl, $\mathrm{Z}$ and Eto) or 2 bacteriostatic (E and $\mathrm{Cs}$ ) drugs are not tolerated. All patients receive drugs under direct observation on 6 days of the week. On the $7^{\text {th }}$ day the oral drugs are to be administered unsupervised whereas injection kanamycin is omitted. If intolerance occurs to the drugs, ethionamide, cycloserine and PAS may be split into two dosages and the morning dose administered under DOT. The evening dose is self-administered. The empty blister packs of the selfadministered doses are checked the next morning during DOT. Pyridoxine should be administered to all patients on an RNTCP Category IV regimen. Drug dosages for MDR-TB cases are decided according to the weight bands. ${ }^{6}$

A longitudinal cohort study was conducted by interviewing MDR TB patients of seven district of central Gujarat, registered at DOTS Plus site-SSGH, Vadodara for DOTS Plus therapy under RNTCP between February 2010 to December 2010. Patients were diagnosed to have MDR-TB if they were found resistant to Isoniazide and Rifampicin with or without resistance to other first line drugs on drug sensitivity testing (DST) results. ${ }^{4}$ All the patients registered during above mentioned period were included in study 
(Whole universe was taken, so sample size calculation was not required). Seriously ill patients, unable to give interview and those patients who did not give consent were excluded.

Ethical clearance was obtained from Scientific Review Board (SRC) and also from Institutional Ethical Committee on Human Research (IECHR), Medical College. Data collection was done with necessary permission in writing from State TB Officer (STO), RNTCP Cell. The District Tuberculosis Officers (DTO) of the aforementioned 7 districts were also informed about this study and their cooperation was solicited. For interviewing patients admitted at the DOTS Plus site for initiation of treatment or management of adverse drug reactions, permission was obtained from the Superintendent. All patients were enrolled in the study after taking written and informed consent in the local language that the patient could understand.

Data collection was carried out from February 2010 to November 2012. The list of study subjects was obtained from DOTS Plus Site. A total of 146 patients were registered in during above mentioned period. Out of the total 146 patients, 142 could be interviewed by pretested structured questionnaire after completion of 6 months and at 24 months of DOTS plus therapy at the DOTS Centre of respective districts when they come to receive treatment or at their homes by home visit. The patients were asked questions related to various ADRs experienced in present treatment and their responses were documented. Efforts were made to get information about ADRs in deceased patients from their relatives; few of the patients who were critically ill at the time of visit were approached after their health improved. Hence the ultimate sample size for the study is 142 . Rest could not be interviewed because of migration, default from treatment, refusal to give consent or death. The patient cards at DOTS Plus Site were used for tracking the rest of the required details related to changed treatment in patients having ADRs.

The data were entered in Microsoft excel version 2007 using strict check files (data validation command) to prevent wrong data entry. Data cleaning was carried out, checked for discrepancies and rectified. Data analysis was done with Epi Info 7.0.8.0.

\section{RESULTS}

In this study, out of 142 patients, 50 were $<30$ years of age, 71 were in 30-50 years group and 21 were $>50$ years of age. Thus, most of the patients were in age group of 3050 years. $71.83 \%$ (102) patients were males \& $28.16 \%$ (40) patients were females with mean age of $34.83 \pm 12.19$ years at starting of study. $26.05 \%$ (37) female patients were in the reproductive age group (15-45 years). $50.71 \%$ of patients were literate, $40.84 \%$ of whom had primary education. However, $49.29 \%$ of patients were illiterate. At the time of interview, $23.24 \%$ of the patients were unemployed. Majority of the patients (46.47\%) of patients had income between 1500-3000 rupees per month, while $9.85 \%$ had income of more than 5000 rupees per month.

Of the patients initiated with MDR-TB treatment, 51.03\% (74) of them were due to previous treatment failure and $1.38 \%$ (2) cases were new freshly diagnosed MDR-TB cases.

Among 142 patients, $48.59 \%$ (69) patients developed ADRs at the end of 6 months of DOTS plus therapy and 54.93\% (78) reported ADRs at 24 months of therapy. Distribution of ADRs among study subjects is shown in Table 1.

As it is shown in Table 1 , the most common side effect reported at $6^{\text {th }}$ month and $24^{\text {rd }}$ month of therapy was GI disturbances, Headache and Arthralgias. Other side

\begin{tabular}{|c|c|c|c|c|}
\hline \multirow{2}{*}{$\begin{array}{l}\text { Adverse Drug } \\
\text { Reactions }\end{array}$} & \multicolumn{2}{|c|}{$\begin{array}{l}\text { After } 6 \text { months of treatment } \\
\qquad(\mathrm{N}=69)\end{array}$} & \multicolumn{2}{|c|}{$\begin{array}{l}\text { After } 24 \text { months of treatment } \\
\qquad(\mathrm{N}=78)\end{array}$} \\
\hline & Frequency & $\%$ & Frequency & $\%$ \\
\hline GI Disturbances & 69 & 100 & 36 & 46.15 \\
\hline Arthralgia & 7 & 10.14 & 10 & 12.82 \\
\hline Headache & 36 & 52.17 & 9 & 11.54 \\
\hline Skin reactions & 3 & 4.35 & 6 & 7.69 \\
\hline Psychiatric symptoms & 0 & 0.00 & 5 & 6.41 \\
\hline Visual disturbance & 1 & 1.44 & 4 & 5.13 \\
\hline Dizziness/Giddiness & 6 & 8.70 & 3 & 3.85 \\
\hline Decreased hearing & 6 & 8.70 & 2 & 2.56 \\
\hline Swelling on face/foot & 1 & 1.44 & 2 & 2.56 \\
\hline Jaundice/Hepatitis & 0 & 0.00 & 1 & 1.28 \\
\hline Others & 0 & 0.00 & 37 & 47.43 \\
\hline
\end{tabular}

${ }^{*}$ Multiple responses possible 


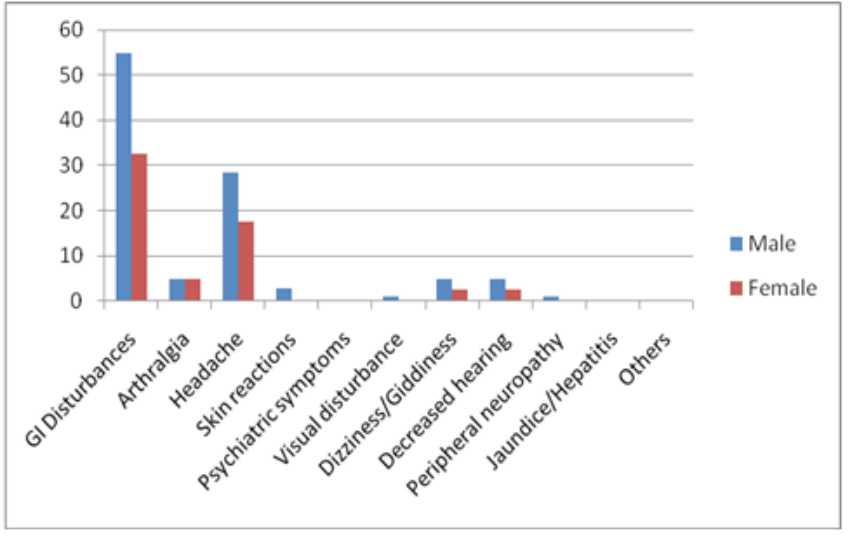

Figure 1: Gender wise distribution of ADRs after 6 months of DOTS plus therapy

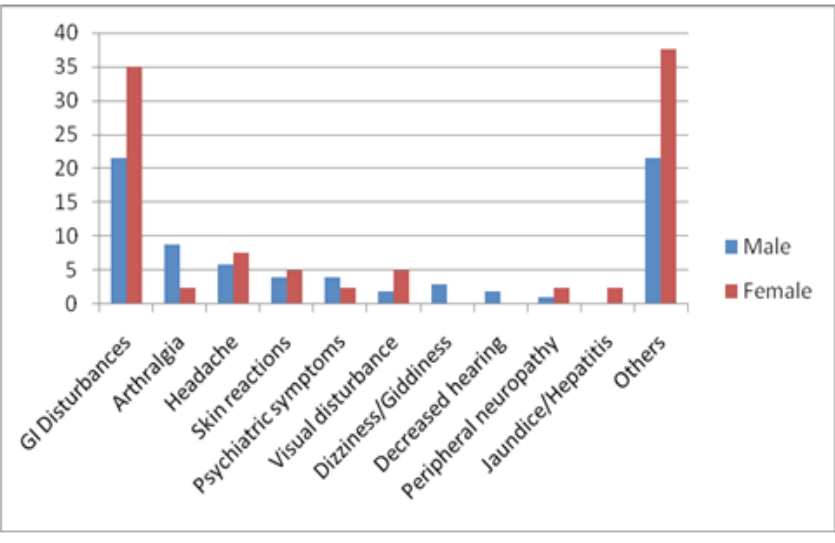

Figure 2: Gender wise distribution of ADRs after 24 months of DOTS plus therapy

\begin{tabular}{|ccc|}
$\begin{array}{c}\text { Table 2: Average Duration of ADRs in MDR-TB treatment } \\
\text { Adverse Drug } \\
\text { Reactions }\end{array}$ & $\begin{array}{c}\text { Median duration of ADR (in days) } \\
\text { After } \mathbf{6} \text { months }\end{array}$ & $\begin{array}{c}\text { After } \text { months } \\
\text { GI Disturbances }\end{array}$ \\
\hline Arthralgia & 60 & 5 \\
\hline Skin reactions & 80 & 4 \\
\hline Peripheral neuropathy & 50 & 17 \\
\hline Decreased hearing & 120 & 315 \\
\hline Dizziness/Giddiness & 135 & 100 \\
\hline Psychiatric symptoms & 90 & 13 \\
\hline Jaundice/Hepatitis & 0 & There is onlyone patient \\
\hline Visual disturbance & 0 & 30 \\
\hline Headache & 135 & 15 \\
\hline
\end{tabular}

\begin{tabular}{|c|c|c|}
\hline $\mathbf{z}$ & $\begin{array}{l}\text { After } 6 \text { month of } \\
\text { Treatment (\%) } \\
\qquad(\mathrm{N}=69)\end{array}$ & $\begin{array}{l}\text { After } 24 \text { months of } \\
\text { Treatment (\%) } \\
(\mathrm{N}=78)\end{array}$ \\
\hline $\begin{array}{c}\text { Symptomatic } \\
\text { treatment }\end{array}$ & 85 & 62.68 \\
\hline $\begin{array}{l}\text { Stopped one or } \\
\text { more drug }\end{array}$ & 4 & 13.43 \\
\hline Specific treatment & 1.16 & 13.43 \\
\hline $\begin{array}{l}\text { Refer to DOTS } \\
\text { plus site \& } \\
\text { treatment change }\end{array}$ & 9.84 & 5.97 \\
\hline $\begin{array}{l}\text { Reduce drug } \\
\text { dosage }\end{array}$ & 0 & 4.47 \\
\hline
\end{tabular}

effects commonly seen included breathlessness, chest pain, hematemesis, weakness, pimples on face and pain and swelling at injection site. GI disturbances, Headache and dizziness/giddiness which were reported at $1^{\text {st }}$ follow up were reduced in later part of treatment when $2^{\text {nd }}$ follow up was taken. Complaints of Arthralgias, Skin reactions, Visual disturbance and swelling on face/foot were increased in later part of treatment. Treatment change was advised in patients with complaint of decreased hearing, so that complaint was reported less during $2^{\text {nd }}$ follow up. Psychiatric symptoms, Jaundice/Hepatitis and other side effects were reported in later part of course of treatment.
Most of the ADRs were noted more in males at first follow up (Figure 1). While during $2^{\text {nd }}$ follow up it was found that all the side effects were more in females except for arthralgias and psychiatric symptoms (Figure 2).

Table 2 shows that the average duration for most of ADR after the initiation of category IV treatment was 2-3 months (60-90 days). Decreased hearing, Peripheral neuropathy and Decreased vision were seen between 3-5 months (90-150 days) after initiation of cat IV treatment.

According to guidelines, symptomatic and specific treatment was given and complaint stopped in most of patients. Some of the patients with complaint of decreased vision, dizziness and psychiatric symptoms required change in treating drugs and reference to special departments through the DOTS Plus Site (Table 3).

\section{DISCUSSION}

Multidrug-resistant tuberculosis (MDR-TB) is an increasing global problem, with most cases arising from a mixture of physician error and patient non-compliance during treatment of susceptible TB. The disease is not only a medical problem or a public health problem but also a 
critical social problem of great magnitude. DOTS-Plus is more complex than the basic DOTS strategy. Baseline information and adequate information on epidemiological factors, various side effects of drugs is required for effective treatment. For DOTS-Plus to be successful, special attention is needed for adherence to difficult-to-take regimens for longer period and side-effect management.

The present study was conducted among the cohort of the year 2010 put on MDR TB treatment registered for DOTS Plus therapy under RNTCP of Vadodara Region. Out of the total 146 patients, data for 142 was obtained.

According to our study, mean age of $35.01 \pm 12.25$ years favours the argument that the disease was common in economically productive age group compared to older age group, indicating an exposure to drug resistant cases in the last two decades. Similar finding was shown in a study done by Bhatt GS et al, (2010) in Ahmedabad, Gujarat where the mean age was $33.64 \pm 11.03$ years. ${ }^{7}$ Similar result was seen in a study by Datta et al, in Kashmir in 2010, where the mean age was $39 \pm 4.7$ years. ${ }^{8}$ However, study done by Cavanaugh et al, in Russia during 2002-2005 has shown that mean ages were 42 years. ${ }^{9}$ Similar result were shown in study of Masjedi et al, during 2002-2006 in Iran, mean ages were $44.38 \pm 19.05$ years. ${ }^{10}$

In this study, there were 102 males (71.8\%) and 40 females (28.2\%), thereby showing higher occurrence of MDR-TB in males as compared to female patients. The male to female ratio in this study was 2:1, similar results were also shown in study done by Cavanaugh et al, in Russia which showed that $83 \%$ were male and $18 \%$ were female. ${ }^{9}$ In a study by Chiang et al, in Taiwan, $71.9 \%$ were males and $28.1 \%$ females(36) and in study of Eker et al, in Germany during 2004-2006, 24\% patients were female (median age 28 years), and $76 \%$ were male (median age 39 years). ${ }^{11}$ But in study of Datta et al, in Kashmir showed that Ratio of male to female was 29:23. ${ }^{7}$ and study of Masjedi et al, in Iran showed that out of these 43, $27(62.8 \%)$ were male and $16(37.2 \%)$ female. $^{10}$

In the present study, almost half of the patients, i.e $48.59 \%(69)$ at $6^{\text {th }}$ month and $54.9 \%(78)$ at $24^{\text {th }}$ month experienced one or the other ADRs of drugs in different frequencies and for different durations as shown in Table 1 and 2. Most patients faced problems mainly after 2-3 months of treatment initiation. Most of these ADRs, in $85 \%$ and $62.68 \%$ (42) were managed by symptomatic treatment. While according to guidelines; skin reaction, psychiatric symptoms dizziness/giddiness, visual disturbance, swelling of face/foot, jaundice/hepatitis- were ADRs that required hospitalization and change in treatment regimen. Similar finding were seen in study done by Bhatt GS et al.

Nathanson E et al, conducted study in five DOTS-Plus sites and the five most common adverse reactions observed were nausea/vomiting, diarrhoea, arthralgia, dizziness/vertigo and hearing disturbances. ${ }^{12}$

In Tamilnadu Pauline J et al, found that the main side effects were GI Disturbances, Giddiness, Arthralgia, insomnia, Swelling/pain at injection site, Skin lesions, Depression, Jaundice, Convulsion, Impaired hearing, Impotence and Visual problems. ${ }^{13}$

In contrast to our finding, Masjedi et al, in Iran found that the most common ADR was hearing loss (46\%), followed by hepatitis $(9.2 \%)$, psychosis/ suicide attempts $(6.9 \%)$ and tinnitus $(2.3 \%) .{ }^{10}$

In our study, $4 \%$ patient at $6^{\text {th }}$ month of treatment and $2.56 \%$ patients at $24^{\text {th }}$ month of treatment with complaint of decreased hearing were put on Para-amino Salicylic acid (PAS) instead of Injection Kanamycin. Arora VK et al, in New Delhi also observed that Injection Kanamycin was stopped in $5 \%$ patients due to hearing loss/giddiness. ${ }^{14}$

In our study $5 \%$ patient at $6^{\text {th }}$ month and $12.82 \%$ patients at $24^{\text {th }}$ month who had complaint of joint pain (arthralgia) were prescribed Tablet Paracetamol (500 mg TDS) initially for a week. After review, if there was no improvement, the dose was increased up to $1000 \mathrm{mg}$ TDS for a week. Whereas, in a study done by Nathanson E et al 11\% had minor joint pain which was managed by symptomatic treatment. ${ }^{12}$ In a study done by Datta et al, (2010) in Kashmir, 13.4\% patients developed arthralgia attributed to pyrazinamide, which was relieved by non-steroidal antiinflammatory drugs in most of the cases. ${ }^{8}$

Patient with complaint of symptoms suggestive of peripheral neuropathy (pins and needles sensation, numbness or pain in the hands or feet with or without signs), Tablet Pyridoxine (20 mg once a day) was prescribed for 2 weeks and the patient reviewed at weekly intervals.

In the current study, specific treatments were required in $1.16 \%$ cases noted in $1^{\text {st }}$ follow up and $13.43 \%$ patients in second follow up while change of drug regimen were required in $9.84 \%$ at first follow up and $5.97 \%$ at second follow up and in $4.47 \%$ patients noted at $24^{\text {th }}$ month of treatment, dose of drugs were reduced. 
A study done by Joseph et al, in Tamil nadu reported that $58 \%$ patients required dose reduction or termination of the offending drug. ${ }^{13}$ Whereas, in Taiwan Chiang et al study, $21.4 \%$ patients had adverse drug reactions that required medication to be stopped. ${ }^{15}$ Another study by Isakidis et $a l$, in Mumbai also noticed that $45 \%$ experienced adverse events, of which only $20 \%$ required change of regimen. ${ }^{16}$

There are several possible explanations for the differences in the number of patients requiring drugs to be removed from the regimen due to ADRs in this study and other studies. These include differences in training, their different experiences with a variety of patients, variation in health care workers ability to detect ADRs and their management.

The time-lag between present treatment ADRs and interview was more which could have resulted in a recall bias.

There is a need for counselling before initiation of treatment, which is again reinforced during treatment. These initiatives can lead to better compliance and minimizing default rate.

\section{CONCLUSION}

ADRs were experienced by more than half of the patients in the study and they increased as the duration of treatment increased. GI disturbances, Headache and Arthalgia were most common ADRs among patients. Most of them were managed by symptomatic treatment.

\section{ACKNOWLEDGEMENTS}

State TB Cell, RNTCP, Gujarat for funding and giving permission for conducting study. Dr A T Leuva, Dean, Medical College Baroda, Dr V S Mazumdar, Professor and Head, Department of PSM, Dr K R Patel, Professor and Head, Department of Pulmonary Medicine and Dr R K Baxi, Professor, Department of PSM, Medical College Baroda, for their incessant support and guidance throughout the study period.

\section{SOURCE OF SUPPORT}

Funded by State TB cell, Gandhinagar, Gujarat.

\section{ABBREVIATION}

$\begin{array}{ll}\text { MDR-TB: } & \text { Multi drug resistant } \\ & \text { tuberculosis } \\ \text { ADRs: } & \text { Adverse drug reactions } \\ \text { RNTCP: } & \text { Revised National Tuberculosis Program } \\ \text { SSGH: } & \text { Sir Sayajirao General Hospital } \\ \text { PAS: } & \text { p-aminosalicylic acid } \\ \text { SRC: } & \text { Scientific Review committee } \\ \text { IECHR: } & \text { Institutional Ethical Committee } \\ & \text { on Human Research } \\ \text { STO: } & \text { State TB Officer } \\ \text { TDS: } & \text { Three times a day }\end{array}$

\section{Highlights of Paper}

- Almost half of the patients in the present study experienced one or the other ADRs of drugs, gastrointestinal symptoms were most common among them. Nearly $2 / 3^{\text {rd }}$ of the patients with ADRs were managed by symptomatic treatment and a few of them required either change of drug, reduction in the dose of drug or stopping the treatment.

\section{Author Profile}

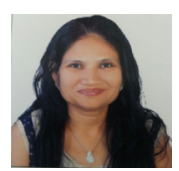

- Dr Sangita Patel: Is an Associate Professor in the Department of PSM, Medical College Baroda and a passionate teacher with 19 years of teaching experience. She did her MD in PSM from M. S. University in 1999. She did her diploma in Industrial health from M. S. University in 2002. She did her graduate certificate course on clinical research methodology from University of South Florida. She has done several research projects funded by NIH UNICEF, WHO, ICMR, Population council and UNFPA. Her Research interests include HIV, Maternal and child health and tuberculosis. She has published more than 60 papers in international and national journals.

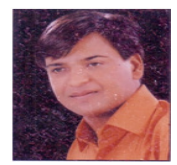

- Dr. Kapil Bhikhubhai Nimavat: M.D. PSM, has had wide experience of Revised National TB control Programme for 13 years. He has been working in the field of public Health since 2002; and has been In-charge Superintendent at Community Health Center for 4 years. He has earlier worked as Senior Medical Officers at District TB center Rajkot for 3 years. 


\section{REFERENCES}

1. World Health Organization. Global Tuberculosis Control: Surveillance, Planning and Financing, Geneva; 2011.

2. Sivaraj R, Umarani S, Parasuraman S, Muralidhar P. Revised National Tuberculosis Control Program regimens with and without directly observed treatment, short-course: A comparative study of therapeutic cure rate and adverse reactions. Perspect Clin Res. 2014; 5(1): 16-9.

3. World Health Organization. Global Tuberculosis Report, Geneva; 2012.

4. Central TB Division DGHS, Ministry of Health \& Family Welfare. DOTS-Plus Guidelines, New-Delhi; 2010.

5. World Health Organization. TB Report; 2012.

6. Holtz TH. XDR-TB in South Africa: Revised Definition. Plos Med. 2007; 4(4): 161.

7. Bhatt GS, Vyas S. An Epidemiological Study of Multi Drug Resistant cases registered under Revised National Tuberculosis Control Programme of Ahmedabad city. Ahmedabad: Gujarat University; 2010.

8. Datta BS, Hassan G, Kadri SM, Qureshi W, Kamili MA, Singh H, et al. Multidrug-resistant and extensively drug resistant tuberculosis in Kashmir, India. J Infect Dev Ctries. 2010; 4(1): 19-23.

9. Cavanaugh JS, Kazennyy BY, Nguyen ML, Kiryanova EV, Vitek E, Khorosheva TM, et al. Outcomes and follow-up of patients treated for multidrug-resistant tuberculosis in Orel, Russia. Int J Tuberc Lung Dis. 2012; 16(8): 1069-74.
10. Masjedi MR, Tabarsi P, Chitsaz E, Baghaei P, Mirsaeidi M, Amiri MV, et al. Outcome of treatment of MDR-TB patients with standardised regimens, Iran. Int J Tuberc Lung Dis. 2008; 12(7): 750-5.

11. Eker B, Ortmann J, Migliori GB, Sotgiu G, Muetterlein R, Centis $\mathrm{R}$, et al. Multidrug- and extensively drug-resistant tuberculosis, Germany. Emerg Infect Dis. 2008; 14(11): 1700-6.

12. Nathanson $E$, Gupta R, Huamani $P$, Leimane $V$, Pasechnikov $A D$, Tupasi TE, et al. Adverse events in the treatment of multidrugresistant tuberculosis: results from the DOTS-Plus initiative. Int $J$ Tuberc Lung Dis. 2004; 8(11): 1382-4.

13. Pauline J, Desai VB, Mohan NS, Fredrick JS, Ramachandran R, Raman $\mathrm{B}$, et al. Outcome of standardized treatment for patients with MDR-TB from Tamil Nadu, India. Indian J Med Res. 2011; 133(5): 529-34.

14. Arora VK, Sarin R, Singla R, Khalid UK, Mathuria K, Singla N, et al. DOTS-Plus for Patients with Multidrug-resistant Tuberculosis in India: Early Results After Three Years. Indian J Chest Dis Allied Sci. 2007; 49(2): 75-9.

15. Chiang CY, Enarson DA, Yu MC, Bai KJ, Huang RM, Hsu CJ, et al. Outcome of pulmonary multidrug-resistant tuberculosis: A 6-yr follow-up study. Eur Respir J. 2006; 28(5): 980-5.

16. Isaakidis P, Cox HS, Varghese B, Montaldo C, Da Silva E, Mansoor $\mathrm{H}$, et al. Ambulatory multi-drug resistant tuberculosis treatment outcomes in a cohort of HIV-infected patients in a slum setting in Mumbai, India. Plos One. 2011; 6(12): e28066. 